\title{
Preparation of Nanocomposite Based on Exfoliation of Montmorillonite in Acrylamide Thermosensitive Polymer
}

\author{
Nader Zabarjad Shiraz, ${ }^{1}$ Elham Enferad, ${ }^{2}$ \\ Aazam Monfared, ${ }^{2}$ and Mohammad Ali Mojarrad ${ }^{3}$ \\ ${ }^{1}$ Department of Chemistry, Islamic Azad University, Central Tehran Branch, Tehran 1467686831, Iran \\ ${ }^{2}$ Department of Chemistry, Payam e Noor University, P.O. Box 19395-3697, Tehran, Iran \\ ${ }^{3}$ Department of Chemistry, Islamic Azad University, Karaj Branch, P.O. Box 31485-313, Karaj, Iran
}

Correspondence should be addressed to Nader Zabarjad Shiraz; zabarjad_sh@yahoo.com

Received 3 January 2013; Accepted 2 February 2013

Academic Editors: S. Fakirov, B. Hazer, A. Mousa, D. Pavel, M. Sanopoulou, and S. Yamazaki

Copyright (C) 2013 Nader Zabarjad Shiraz et al. This is an open access article distributed under the Creative Commons Attribution License, which permits unrestricted use, distribution, and reproduction in any medium, provided the original work is properly cited.

Poly( $N$-isopropylacrylamide) (PNIPAM) was synthesized in the presence of AIBN as radical initiator. The structure of polymer was elucidated using IR, ${ }^{1} \mathrm{H}$ NMR, and ${ }^{13} \mathrm{C}$ NMR spectroscopies and TGA thermogram. Exfoliated nanocomposite based on thermosensitive polymer (PNIPAM) was prepared utilizing montmorillonite (MMT) by solution blending. Its dispersion characteristics were investigated using SEM, X-ray diffraction, and particle size analysis. XRD showed exfoliation of MMT in polymer matrix above lower critical solution temperature (LCST). SEM indicated that polymer chains were dispersed among the layers of MMT. Particle size analysis showed two distinctive regions at 311 (31/5\%) and 1160 (68/5\%) nm.

\section{Introduction}

The production of clay-polymer nanocomposites is an active area of research which benefits from the high surface area ratio of nanoclay particles to greatly improve the thermomechanical properties of the polymer matrix, even with low filler contents [1]. The success in the development of clay-polymer nanocomposites requires two key conditions: first, achieving a correct dispersion of nanoparticles in the matrix in order to obtain a high fraction of interfacial claypolymer region within the material, and second, controlling the interfacial interactions between silicate particles and the polymer matrix, so that highly interacting polymer chains can either intercalate between the silicate layers or even break the stacking of the basal planes to induce exfoliation [2-4].

The ultimate goal for the preparation of nanocomposites is to achieve a very high degree of dispersion (exfoliation) of the aggregates of layered silicates. However, perfect exfoliation of the aggregates of layered silicates is very difficult to be achieved, if not impossible [5]. There are three ways of preparing nanocomposites, namely, (1) in situ polymerization of a monomer using an initiator tethered to the silicate surface or copolymerization of monomers by a silicate-anchored bifunctional initiator, (2) solution blending, and (3) melt blending [2].

It is well established that layered silicates (e.g., montmorillonite (MMT)) are hydrophilic [6, 7]. Therefore, they do not have chemical affinity with hydrophobic organic polymers and thus the two are incompatible.

Thermosensitive polymers [8], such as poly( $N$-isopropyl acrylamide) (PNIPAM) [9-11], exhibit a volume phase transition at a critical temperature, which causes a sudden change in the solvation state. Such polymers, which become insoluble and hydrophobic upon heating, have a lower critical solution temperature (LCST) [11].

PNIPAM is hydrophilic below the LCST (about $32^{\circ} \mathrm{C}$ ) and there is no considerable interaction between polymer 


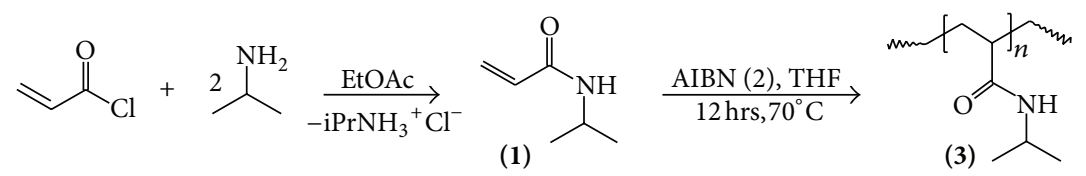

SCHEME 1

and the suspended particles, but above LCST hydrophobichydrophobic interactions occur between polymer and particles, which lead to shrinkage of the polymer and sorption of suspended particles [12].

To our knowledge, some studies have been reported on the preparation of exfoliated MMT nanocomposites based on thermosensitive polymers $[13,14]$. This paper aims to summarize the highlights of our findings from the investigation on exfoliation ability of PNIPAM as thermosensitive polymer using XRD and SEM techniques and particle size analysis.

\section{Materials and Methods}

Montmorillonite (MMT) nanoclay powder with cation exchange capacity of $92 \mathrm{meq} / 100 \mathrm{~g}$ of clay was provided by Southern Clay Products (under the trade name of $\mathrm{Na}$ Cloisite, USA). The average dry particle size is $8 \mu \mathrm{m}$, composed of millions of individual platelets that only appear separately after a good dispersion in a polymer or a liquid dispersant. IR spectra were measured by a Shimadzu IR 460 spectrometer. ${ }^{1} \mathrm{H}$ and ${ }^{13} \mathrm{C}$ NMR spectra were measured with BRUKER DRX-500 AVANCE spectrometer at 500 and 125.8 MHz, respectively. XRD patterns were obtained at ambient temperature using a XRD 6000 Shimadzu diffractometer, at $1^{\circ} / \mathrm{min}$ in a $2 \theta$ range between 2 and $24^{\circ}$ using Ni-filtered $\mathrm{Cu} \mathrm{KR}$ radiation. SEM images were obtained with VEGA// TESCAN-LMU, using an accelerating voltage of $25 \mathrm{kV}$. Metler Tolido TGA/DSC 1 Star System was used for TGA analysis. Master sizer (Zen 3600 Malvern) was employed for particle size analysis.

2.1. The Procedure for the Synthesis of NIPAAM (1) [15]. Acryloyl chloride $(0.4 \mathrm{~mol})$ and isopropylamine $(0.8 \mathrm{~mol})$ were added to $15 \mathrm{~mL}$ ethyl acetate in a $100 \mathrm{~mL}$ reactor equipped with a magnetic stirrer. The reactor was placed in an iced water bath to control the reaction temperature at $0^{\circ} \mathrm{C}$ for $4 \mathrm{~h}$. The mixture was filtered and the obtained filtrate solution remained $24 \mathrm{~h}$ in a refrigerator; after vacuum distillation at $80^{\circ} \mathrm{C}$, the collected precipitate was filtered and dried at room temperature (r.t).

2.2. The Procedure for the Synthesis of PNIPAM (3). A solution of NIPAAM ( $4 \mathrm{gr}$ in $16 \mathrm{~mL}$ THF) and AIBN (0.5 gr) was magnetically stirred and refluxed at $70^{\circ} \mathrm{C}$ for $12 \mathrm{hrs}$ under $\mathrm{N}_{2}$ effluent. Precipitated solid was filtered and washed by $2 \times 10 \mathrm{~mL}$ diethyl ether and dried at r.t. $(3.76 \mathrm{~g}, 94 \%)$. IR ( $\nu_{\max }$, $\left.\mathrm{cm}^{-1}\right)(3)(\mathrm{KBr}): 3277(\mathrm{NH}), 1680(\mathrm{C}=\mathrm{O}) .{ }^{1} \mathrm{HNMR}(500 \mathrm{MHz}$, $\left.\mathrm{CDCl}_{3}\right) \delta: 1.12$ and $1.13\left(6 \mathrm{H}, 2 \mathrm{~d}^{3} \mathrm{~J}_{\mathrm{HH}}=7.1 \mathrm{~Hz}, 2 \mathrm{CH}_{3}\right), 1.71(1 \mathrm{H}$, $\left.\mathrm{dd},{ }^{2} \mathrm{~J}_{\mathrm{HH}}=3.0 \mathrm{~Hz},{ }^{3} \mathrm{~J}_{\mathrm{HH}}=7.1 \mathrm{~Hz}, \mathrm{CH}_{2}\right), 1.84\left(1 \mathrm{H}, \mathrm{dd},{ }^{2} \mathrm{~J}_{\mathrm{HH}_{\mathrm{H}}}=\right.$ $\left.5.2 \mathrm{~Hz},{ }^{3} \mathrm{~J}_{\mathrm{HH}}=7.1 \mathrm{~Hz}, \mathrm{CH}_{2}\right), 2.11\left(1 \mathrm{H}, \mathrm{dd},{ }^{3} \mathrm{~J}_{\mathrm{HH}}=5.2 \mathrm{~Hz},{ }^{3} \mathrm{~J}_{\mathrm{HH}}\right.$
TABLE 1: Distinctive peaks of the stretching vibrations $\left(\mathrm{cm}^{-1}\right)$.

\begin{tabular}{lccc}
\hline & $\mathrm{O}-\mathrm{H}$ & $\mathrm{C}=\mathrm{O}$ & $\mathrm{Si}-\mathrm{O}-\mathrm{Si}$ \\
\hline MMT & 3626 & - & 1100 \\
PNIPAM & - & 1680 & - \\
PNIPAM/MMT & 3630 & 1680 & 1080 \\
\hline
\end{tabular}

$=7.1 \mathrm{~Hz}, \mathrm{CHCO}), 3.73(1 \mathrm{H}, \mathrm{m}, \mathrm{CHN}), 8.48(\mathrm{NH}) .{ }^{13} \mathrm{CNMR}$ $\left(125.8 \mathrm{MHz} \mathrm{CDCl}_{3}\right) \delta: 19.1$ and $19.3\left(2 \mathrm{CH}_{3}\right), 25.1\left(\mathrm{CH}_{2}\right), 29.6$ $(\mathrm{CH}), 44.2(\mathrm{CH}-\mathrm{N}), 174.6(\mathrm{C}=\mathrm{O})$.

2.3. MMT Exfoliation in Polymer (3) Matrix. A solution of $2 \mathrm{~g}$ PNIPAM (3) in water $(1 \% \mathrm{w} / \mathrm{v})$ was prepared at room temperature. Nanoclay mixture of MMT in water $(0.1 \mathrm{~g}$ in $5 \mathrm{~mL}$ water) was added to the solution $(60 \mathrm{ml})$ and mixed seriously. After 3 hours temperature was raised slowly to $70^{\circ} \mathrm{C}$. At $32^{\circ} \mathrm{C}$, turbidity of the mixture increased; however, no precipitate or flocculation was observed up to $70^{\circ} \mathrm{C}$ after 8 hours. A layer (200 microns) of suspended mixture was applied on a glass plate, water was evaporated at $20^{\circ} \mathrm{C}$, and subsequently the residue (composition of $15 \% \mathrm{~W} / \mathrm{W}$ of MMT/PNIPAM, theoretically) remained as a transparent film. In this paper, exfoliation ability of the thermosensitive polymer (3) was intended to evaluate in MMT-water suspension mixture at below and above LCST.

\section{Results and Discussion}

Polymerization of NIPAAM (1) in the presence of AIBN (2) as radical initiator led to formation of PNIPAM (3) in good yield (94\%) (Scheme 1) [16, 17].

The structure of polymer (3) was elucidated by IR, ${ }^{1} \mathrm{H} \mathrm{NMR}$, and ${ }^{13} \mathrm{C}$ NMR spectroscopies. In IR spectrum, stretching vibration of $\mathrm{NH}$ and $\mathrm{C}=\mathrm{O}$ groups appeared at 3277 and $1680 \mathrm{~cm}^{-1}$, respectively. In ${ }^{1} \mathrm{H}$ NMR resonance of $\mathrm{CHCO}$ and $\mathrm{CHN}$, polymer backbone was at 2.11 and 3.73 ppm, and resonance of $\mathrm{NH}$ moiety appeared at $8.48 \mathrm{ppm}$. ${ }^{13} \mathrm{C}$ NMR spectrum of product was in good agreement with corresponding polymer structure (3) (experimental).

An important key to obtain a polymer-clay nanocomposite is to achieve a satisfactory dispersion of the nanoclay in the polymer matrix. This requires an efficient interaction between nanoclay and matrix allowing the polymer chains to be inserted within the interlayer of the MMT structure leading to intercalated or exfoliated structures.

Polymer (3) was employed to prepare nanocomposite using MMT (experimental). Some investigations were carried out to investigate the existence, intercalation and/or 


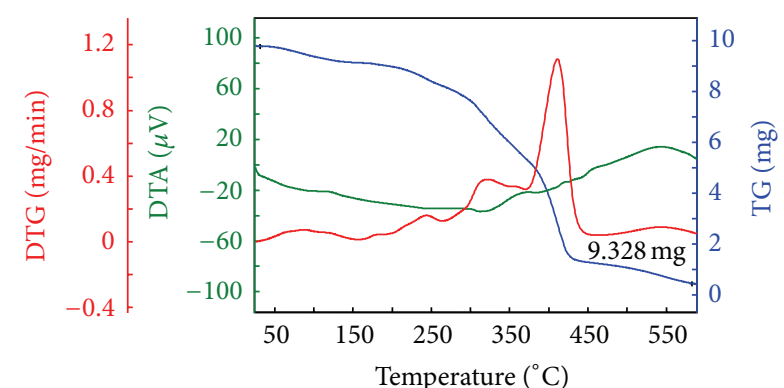

(a)

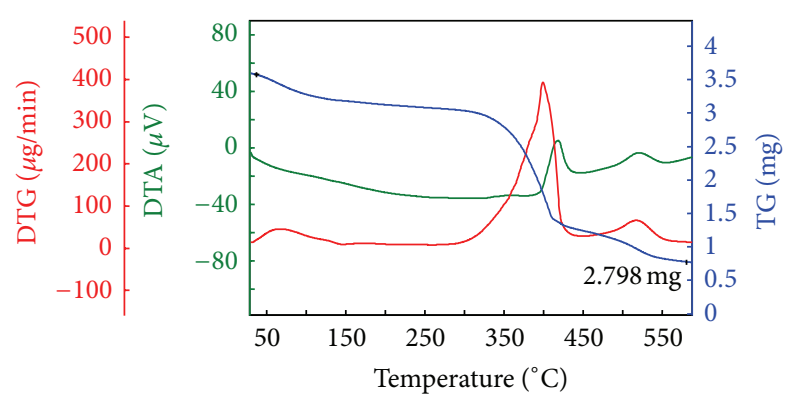

(b)

FIGURE 1: (a) TGA thermograph of (3), and (b) MMT/PNIPAM nanocomposite.

TABLE 2: TGA results of PNIPAM-copolymer and the organoclay/PNIPAM nanocomposite.

\begin{tabular}{lcc}
\hline & PNIPAM & MMT/PNIPAM \\
\hline Initial weight loss $\left({ }^{\circ} \mathrm{C}\right)$ & $95-106$ & $97-106$ \\
$\% \mathrm{~W} / \mathrm{W}$ loss (weight loss) & 9.09 & 9.86 \\
The first degradation ${ }^{\circ} \mathrm{C}$ & $225-415$ & $320-415$ \\
$\% \mathrm{~W} / \mathrm{W}$ loss (final degradation) & 86.11 & 75.00 \\
\hline
\end{tabular}

exfoliation of organoclay layer in PNIPAM matrix. Considering IR spectra, distinctive peaks of organoclay, PNIPAM, and MMT/PNIPAM nanocomposite showed the presence of organoclay in PNIPAM-matrix (Table 1).

The results of TGA thermograms of PNIPAM (Figure 1(a)) and MMT/PNIPAM (Figure 1(b)) have been summarized in Table 2. Initial weight loss of (3) and nanocomposite occurred at about $100^{\circ} \mathrm{C}$, which was due to departure of $\mathrm{H}_{2} \mathrm{O}$ imbedded in the polymer. In the second phase, degradation of (3) and nanocomposite commenced at 225 and $320^{\circ} \mathrm{C}$ for, respectively, and finalized at $415^{\circ} \mathrm{C}$ for both of them. Approximately the whole (3) degraded at less than $430^{\circ} \mathrm{C}$. However, $15.14 \%$ of the composite remained unchanged up ro $600^{\circ} \mathrm{C}$ which was due to MMT. This result was in good agreement with theoretical value (experimental). On the other hand, dispersion of MMT in PNIPAM improved the heat stability of polymer $95^{\circ} \mathrm{C}(225$ to $320^{\circ} \mathrm{C}$ ) (Table 2).

Particle size analysis showed two distinct regions at 311 and $1160 \mathrm{~nm}$ with $31 / 5 \%$ and $68 / 5 \%$ intensities which were due to MMT and PNIPAM particles, respectively (Figure 2). Although particle size distribution was not completely in nanotechnology scale (less than $100 \mathrm{~nm}$ ), it is roughly acceptable to be considered as nano dispersion.

The surface morphology and external structure of PNIPAM/MMT were investigated by scanning electron micrographs which are given in Figure 3. The surface of PNIPAMMMT had a smooth and relatively homogeneous appearance. As clearly seen here, the surface of the exfoliated MMT had a layer shape. The size of the pores between the clusters as shown in Figure 3 was variable (e.g., 422, 960, and $2134 \mathrm{~nm}$ ). It is evident that layers of MMT had been exfoliated in PNIPAM matrix.

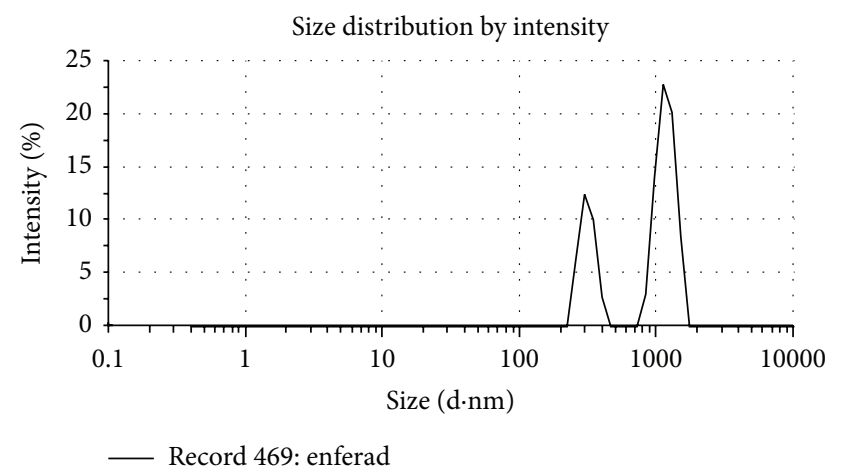

FIgURE 2: Particle size analysis of PNIPAM/MMT suspension.

Dispersion characteristics of solution-blended nanocomposite were studied based on XRD patterns. It can be seen in Figure 4 that the XRD patterns of the nanocomposite showed reflection peaks at 20.1 suggesting that this composite had no dispersion of MMT aggregates below LCST. In spite, above LCST for MMT-hybrid material, MMT characteristic peaks decreased in intensity or even disappeared, meaning a high degree of intercalation and/or exfoliation of the silicate layers in PNIPAM matrix [18]. An explanation for the observed exfoliation is that above LCST intercalated PNIPAM chains had to change their conformation and this provided sufficient energy to exfoliate MMT layers.

\section{Conclusions}

PNIPAM was synthesized via free radical polymerization and its exfoliation ability has been evaluated in MMT-water suspension. Surprisingly in spite of the common coagulation character of thermosensitive polymers, homogeneous suspension of polymer and MMT was formed and was stable within a week. An explanation may be that tendency of thermosensitive polymers to change their conformation above LCST after intercalation to layers of MMT forced the clay to be exfoliated in PNIPAM matrix. Scanning electron microscopy (SEM) images, X-ray diffraction (XRD), and size distribution spectra were carried out and showed that MMT had been exfoliated in polymer matrix. It is suggested to 


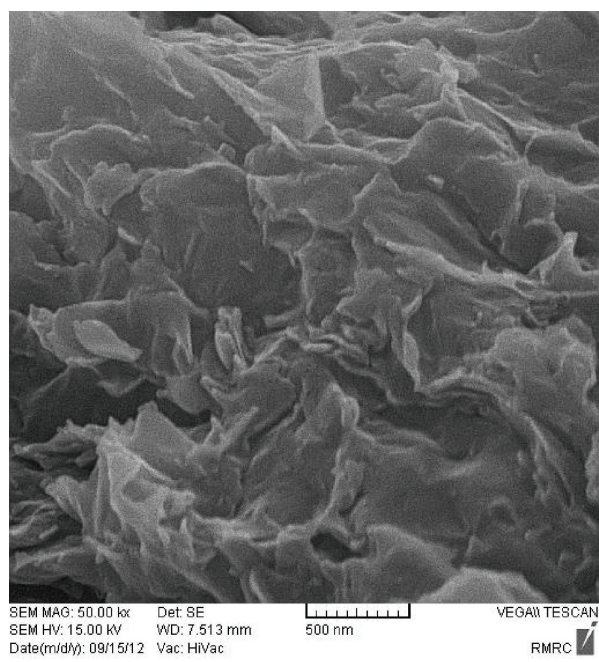

(a) Scale bar $500 \mathrm{~nm}$

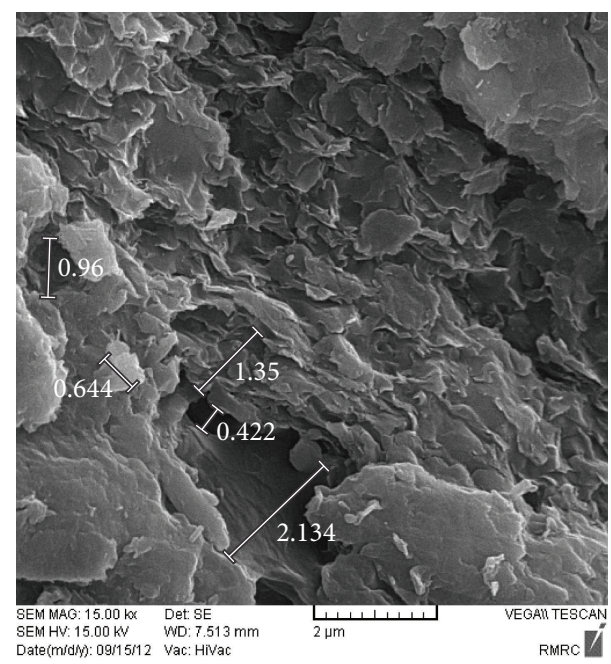

(b) Scale bar $2 \mu \mathrm{m}$

FIGURe 3: SEM image of (a) PNIPAM and (b) exfoliated MMT dried film.

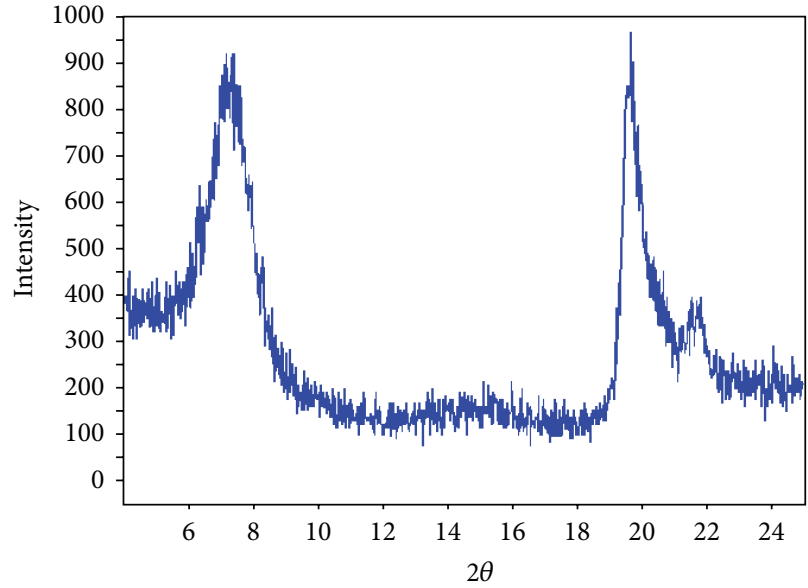

(a)

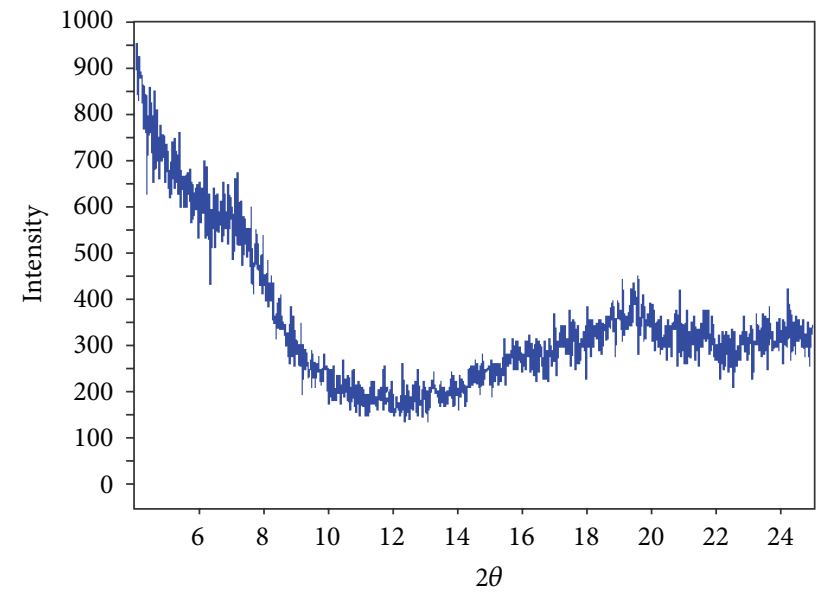

(b)

FIGURE 4: XRD patterns of PNIPAM/MMT hybrid (a) below LCST and (b) above LCST.

use modified clay, named organoclays, to achieve perfect exfoliated nanocomposite.

\section{References}

[1] Z. Martín, I. Jiménez, M. Ángeles Gómez, H. W. Ade, D. A. Kilcoyne, and D. Hernádez-Cruz, "Spectromicroscopy study of intercalation and exfoliation in polypropylene/montmorillonite nanocomposites," The Journal of Physical Chemistry B, vol. 113, pp. 11160-11165, 2009.

[2] S. S. Ray and M. Okamoto, "Polymer/layered silicate nanocomposites: a review from preparation to process," Progress in Polymer Science, vol. 28, p. 1539, 2003.

[3] E. T. Thostenson and C. L. T. W. Chou, "Nanocomposites in context," Composites Science and Technology, vol. 65, pp. 491516, 2005.
[4] K. Kalaitzidou, H. Fukushima, H. Miyagawa, and L. T. Drzal, "Flexural and tensile moduli of polypropylene nanocomposites and comparison of experimental data to Halpin-Tsai and Tandon-Weng models," Polymer Engineering and Science, vol. 47, no. 11, pp. 1796-1803, 2007.

[5] W. Zha, C. D. Han, H. C. Moon, S. H. Han, D. H. Lee, and J. K. Kim, "Exfoliation of organoclay nanocomposites based on polystyrene-block-polyisoprene-block-poly(2-vinylpyridine) copolymer: solution blending versus melt blending," Polymer, vol. 51, no. 4, pp. 936-952, 2010.

[6] R. E. Grim, Clay Mineralogy, McGraw Hill, New York, NY, USA, 2nd edition, 1968.

[7] B. K. Theng, The Chemistry of Clay-Organic Reactions, Wiley, New York, NY, USA, 1974.

[8] V. Aseyev, H. Tenhu, and F. M. Winnik, "Non-ionic thermoresponsive polymers in water," Advances in Polymer Science, vol. 
242, pp. 29-89, 2011.

[9] S. Aoshima and S. Kanaoka, "Synthesis of stimuli-responsive polymers by living polymerization: poly $(N$-isopropylacrylamide) and poly(vinyl ether)s," Advances in Polymer Science, vol. 210, no. 1, pp. 169-208, 2008.

[10] A. Alli and B. Hazer, "Synthesis and characterization of poly $(N-$ isopropyl acryl amide)-g-poly(linolenic acid)/poly(linolenic acid) graft copolymers," Journal of the American Oil Chemists' Society, vol. 88, no. 2, pp. 255-263, 2011.

[11] S. Allı, A. Allı, and B. Hazer, "Hyperbranched homo and thermoresponsive graft copolymers by using ATRPmacromonomer initiators," Journal of Applied Polymer Science, vol. 124, pp. 536-548, 2012.

[12] W. F. Lee and Y. T. Fu, "Effect of montmorillonite on the swelling behavior and drug-release behavior of nanocomposite hydrogels," Journal of Applied Polymer Science, vol. 89, no. 13, pp. 3652-3660, 2003.

[13] M. Dalaran, S. Emik, G. Güçlü, T. B. Iyim, and S. Özgümüş, "Removal of acidic dye from aqueous solutions using poly(DMAEMA-AMPS-HEMA) terpolymer/MMT nanocomposite hydrogels," Polymer Bulletin, vol. 63, no. 2, pp. 159-171, 2009.

[14] J. Aalaie and A. Rahmatpour, "Preparation and swelling behavior of partially hydrolyzed polyacrylamide nanocomposite hydrogels in electrolyte solutions," Journal of Macromolecular Science B, vol. 47, no. 1, pp. 98-108, 2007.

[15] H. G. Schild, "Poly( $N$-isopropylacrylamide): experiment, theory and application," Progress in Polymer Science, vol. 17, pp. 163249, 1992.

[16] C. L. McCormick, B. S. Sumerlin, B. S. Lokitz, and J. E. Stempka, "RAFT-synthesized diblock and triblock copolymers: thermally-induced supramolecular assembly in aqueous media," Soft Matter, vol. 4, no. 9, pp. 1760-1773, 2008.

[17] E. S. Gil and S. M. Hudson, "Stimuli-reponsive polymers and their bioconjugates," Progress in Polymer Science, vol. 29, p. 1173, 2004.

[18] A. Hedayati and A. Arefazar, "Multi-scale analysis of polypropylene based organoclay containing composites, part 1: morphology," Polymer Testing, vol. 28, no. 2, pp. 128-138, 2009. 

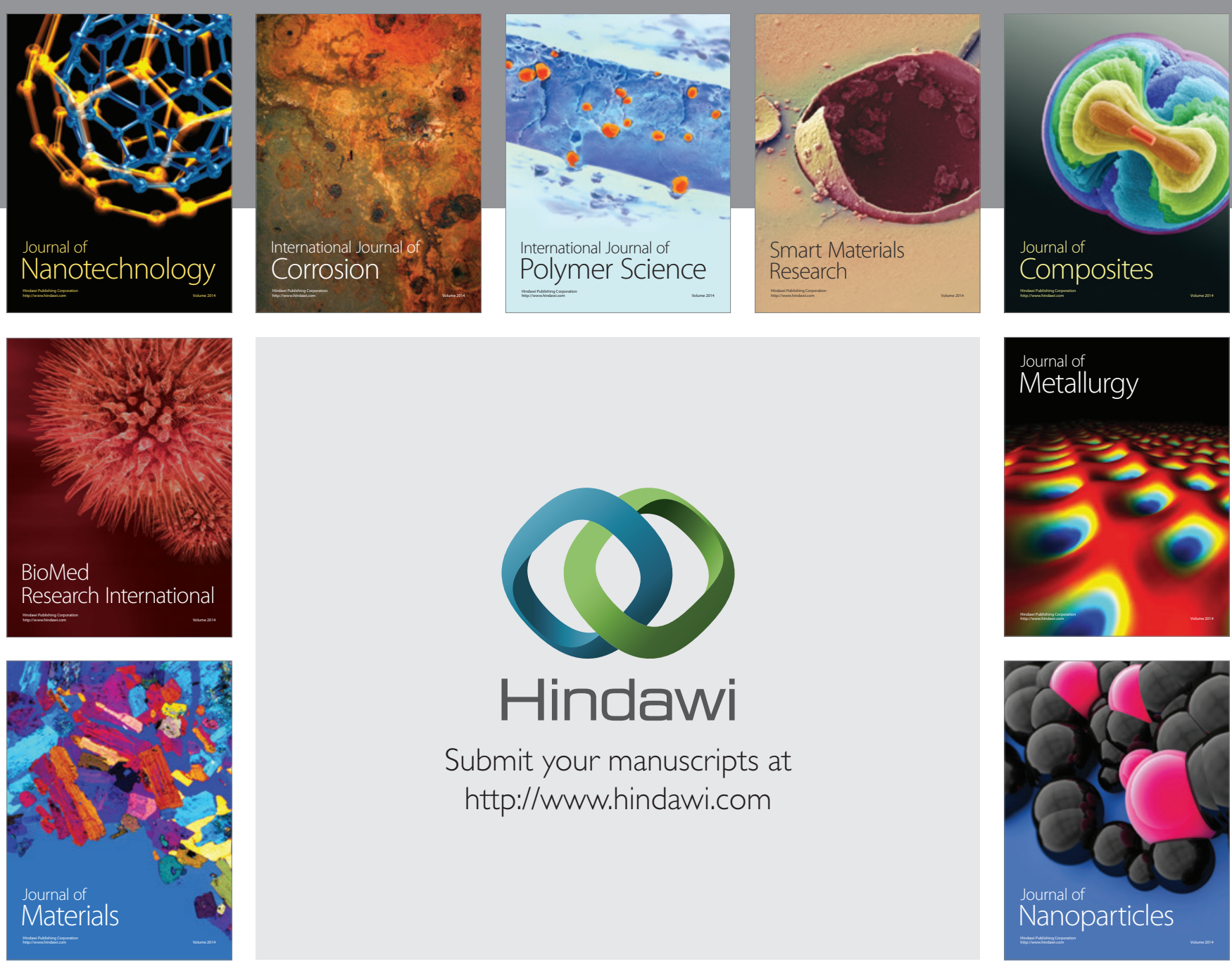

Submit your manuscripts at http://www.hindawi.com
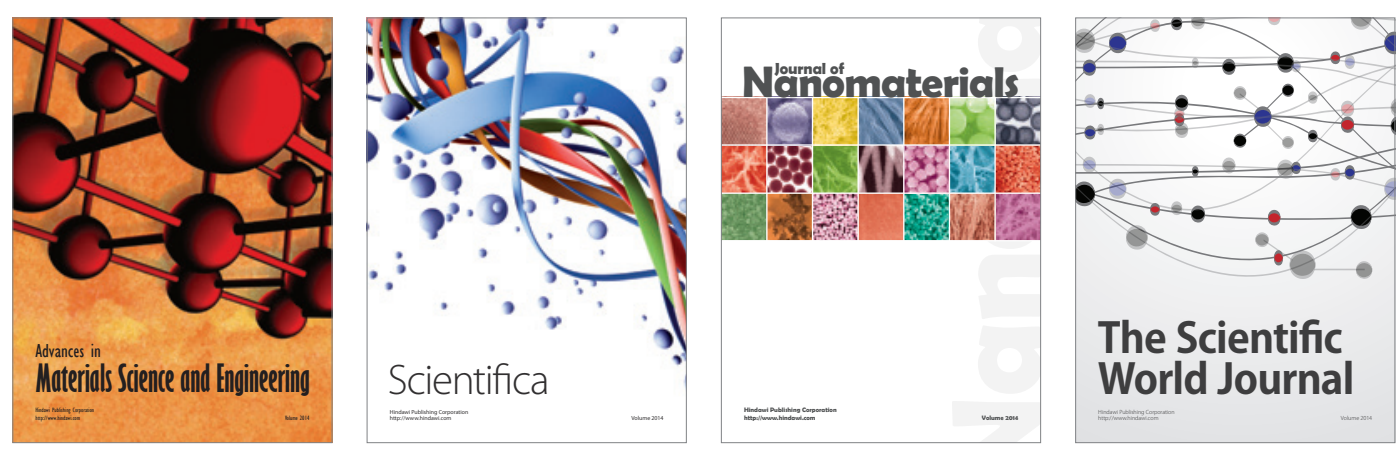

\section{The Scientific World Journal}
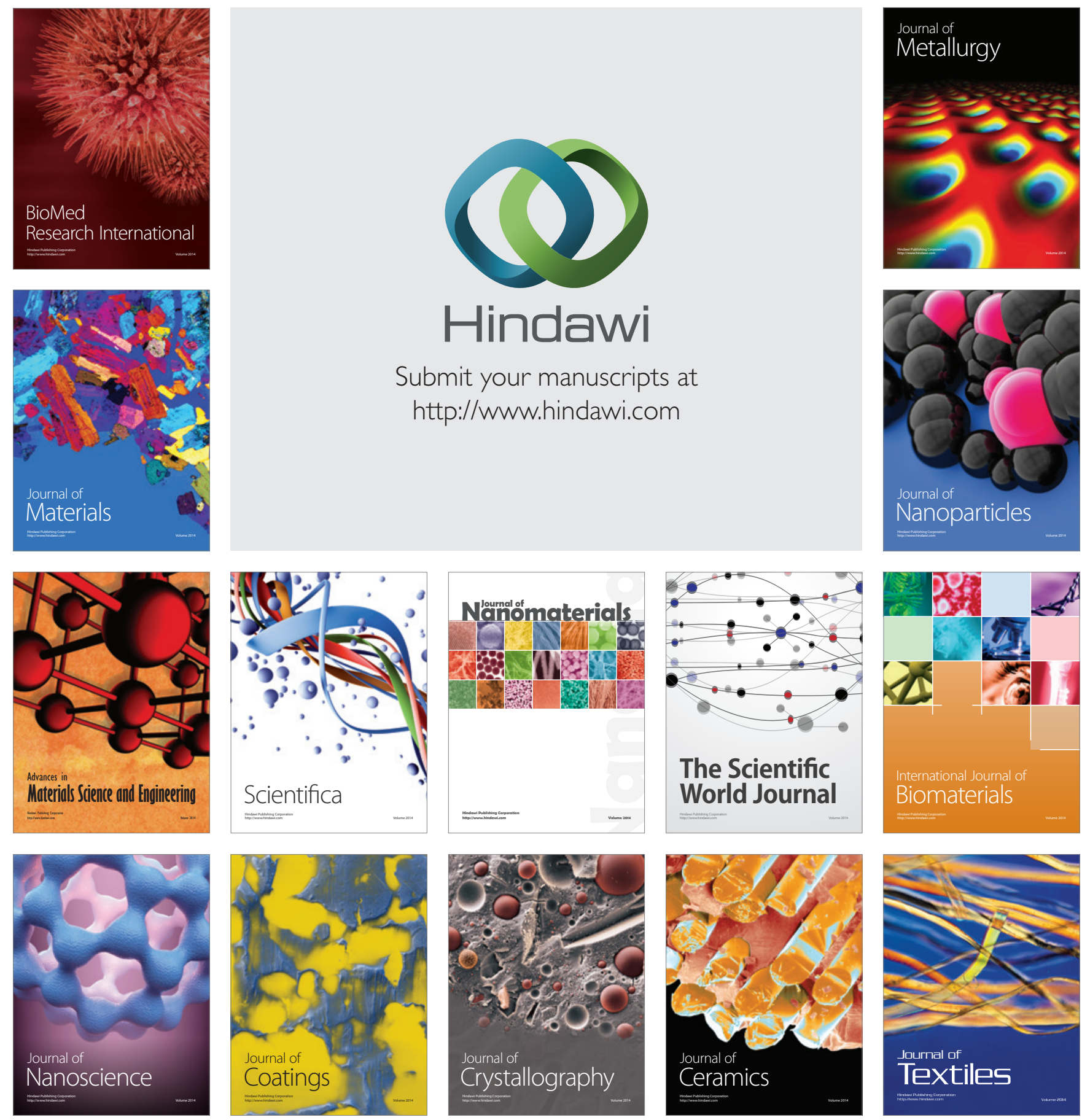